A NOVEL BALANGED DOOR.

It would seem that there could be no further field for invention in so long used and commonplace a device as a door. Yet a Belgian inventor, Mr. Joseph Henri Dierickx, has recently produce a door which is a radical departure from any type heretofore used. It consists of two leaves, which are so pivoted that they will swing into partitions as the door opens, leaving an entirely clear passageway. Thus, the new doors partake of the advantages of both the hinged type and the sliding type, while avoiding their objectionable features. The common, hinged door has heretofore been considere the most satisfactory type where space allows of open. It will not jam except in the unusual event of the door frame settling and thus becoming distorted. But it requires considerable space which, in many in stances, cannot be spared. In street cars, for example, a door of this sort would be constantly blocked by passengers standing in the aisles and on the platforms. Then, too, if the will spring open at every lurch of the car, or be blown open by drafts. The sliding door, while it overcomes these objections, is nevertheless not perfect. The rollers on which it travels are too apt to slip off the track, causing the door to stick and jam. Mr. Dierickx's oor is admirably adapted for street-car use because it overcomes all the objections above noted. It is, further ars, possessing the advantage that it cannot slide open under the jar of cars bumping together. The new door is formed of

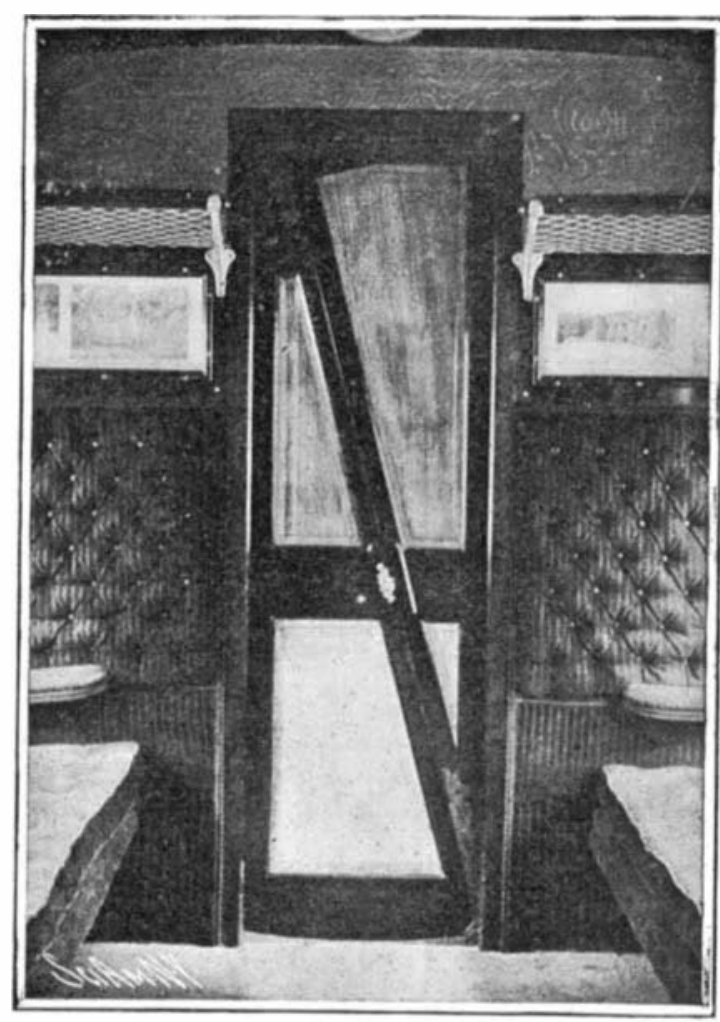

A Passenger Car Equipped with the Novel Balance Door. that we have always been accustome to rectangular doors. There is no reason why a diagonal door should not be as artistically arrange as any other. It will certainly affor architects an excellent opportunity to develop new and striking designs.

The counterbalancing feature of the door is one of the strongest points in its favor. A striking illustration of this was to be seen at the St. Louis Exposition, where a door of this type was used at the entrance of the Belgian pavilion. The loor weighed 1,700 pounds, yet it could be opene by the pressure of a single finger, and it was never out of order during the entire season.

MANNING OARS AND HALYARDS AS A SUMMER OUTING.

$$
\text { BY MAJ }
$$

Something of the soldier's training has been welded into many schools. Not so with the sailor's. There are miniature West Points in almost every State, but schools modele after Annapolis are not so easy to find. Were you to look for such a school in the most likely place, on the Atlantic or Pacific seaboard, you would seek it in vain. As a matter of fact, the only spot at present where you will find the combination of jackie and schoolboy is on an inland lake in a Western State, on Lake Maxinkuckee, at Culver, In Nor is even this an all-year-round affair, but a summer school that contents itself with a brief eight weeks' session, in which man-of-war cutters play a more prominent part than classrooms; and in which the hardening of mus.

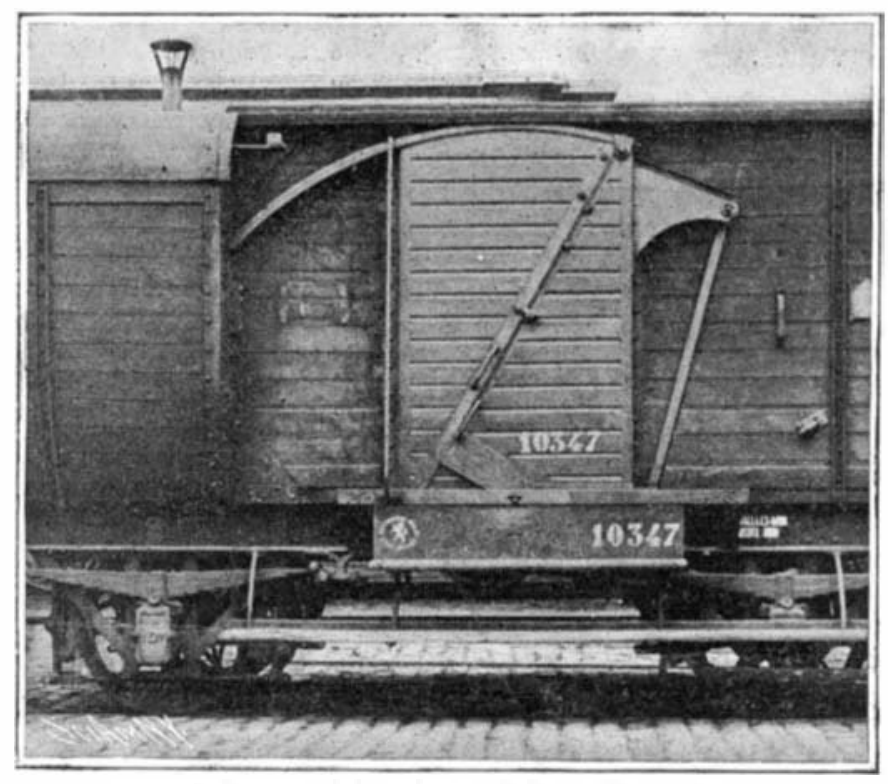

The Balanced Door Applied to a Freight Car.

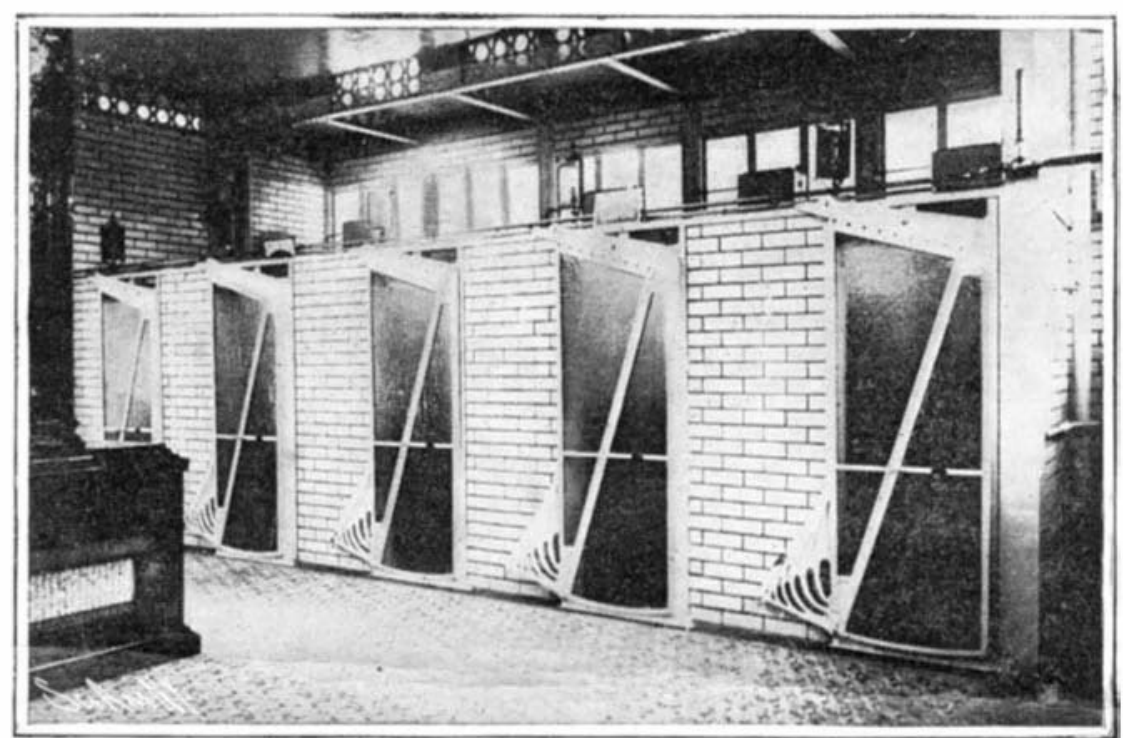

The Public Baths at Brussels Fitted with the Balanced Doors.

A NOVEL BALANCED DOOR.

two triangular leaves which, when the door is closed, meet on a diagonal line of junction. The leaf which is largest at the top is pivote at the lower corner, and the other leaf is swung from a pivot above the center of the doorway. A rod connects the two leaves in such manner that when either one is swung in a certain direction, the other will swing in the opposite direction. Thus, in opening the loor, it is not necessary to seize both leaves and move them, for if either leaf is moved into or out of its pocket, the other will automatically move in harmony with it. The two leaves are also so connected that they counterbalance each other, and they are controlled in their movements by suitably groove guides, in which they travel with a minimum of friction. No rollers are necessary.

Aside from its use for street and railway cars, this door will be found useful for private houses, hotels, ships, etc. In

fact, its uses are unlimite for it will operate in the horizontal plane, as well as in the vertical, and may, therefore, be used for windows, transoms, and the like. The peculiar shape of the door is apt to strike one awkwar at first, but this is due mainly to the fact

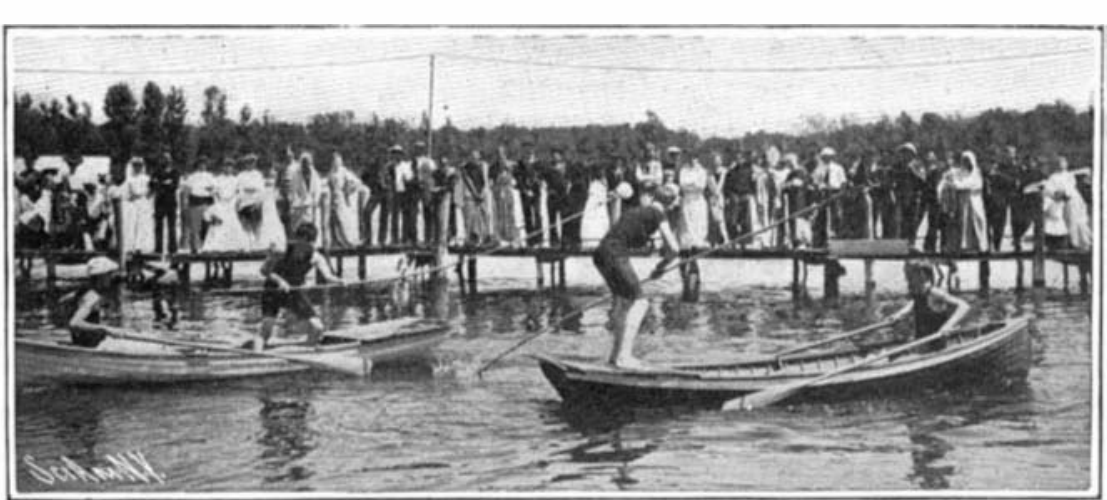

A Water 'l'ilting Match. cles, and the getting of a healthy coat of tan, take precedence over even such things as Latin and Greek. But despite its briefness, it is a session which amply justifies itself by the wealth the tire school-boy. It commends itself also to Uncle Sam by reason of the interest in the navy it arouses among the Western youth, and because the training they receive should make of them good material for officers of the naval militia. In fact, the Navy Department has sent out to this little Desternent he lake a cutters similar to those use in the boat drills of the midshipmen at Annapolis, and has lent Hotchkiss guns and other expensive equipment.

It is not in keeping with the hustling spirit of to-day that a boy even in summer time should spend three long months without aim or purpose, and so summer camps and other forms of organized vacations have come into existence. But it

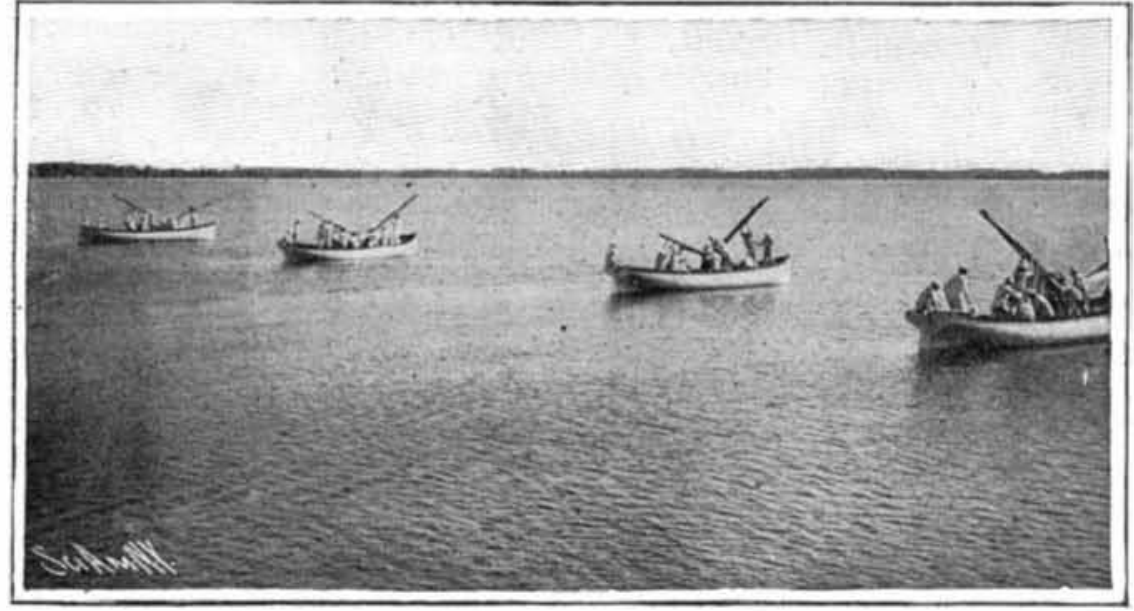

"Up Masts."

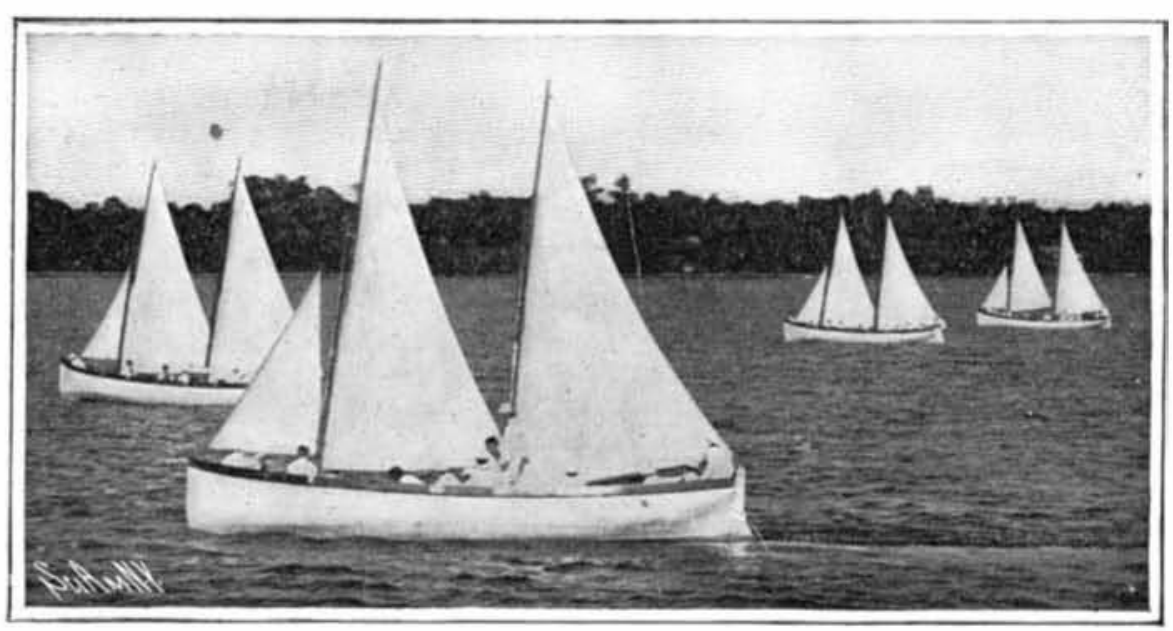

Cutter Drill under Sail. 
is doubtful if any of these make such a strong appeal to a boy's natural tastes, or give him more wholesome refreshment, a browner skin, or harder muscles than this naval course.

Certainly, boys could not enter into a thing with keener zest and more enthusiasm than is put into the manning of oars and halyards by the cadets of Culver Summer Naval School. Even an old man-of-war's man would not disapprove of the seamanly way in which they get up masts and make sail, or of the precision with which they handle their oars, and of the long, steady stroke with which they make the big cutters fairly jump through the water.

Under any conditions a boy loves to row and sail, but possibly the secret of the extra enthusiasm of the Culver lads lies in the appeal that a war cutter makes to the love of romance inherent in every boy; for are not these cutters the landing boats and messengers of the navy? Were they not use in cutting the cable at Cardenas, and in landing troops in Cuba, and in fact would not the history of our navy be incomplete without them?

The nautical appearance of the cutters, with their spotless paint and shining brasswork, and of their canvas-clad crews, also lends interest to the work. And, besides, a cutter drill under oars, or sail, is a far different thing from plain rowing or sailing. Under rowing or sailing. Under
oars a pennat flies in the bow, and the Unite States colors from the stern. The masts are unstepped, and with sails neatly made up, are laid along the running board. One calet perched in the coxswain's box handles the tiller and gives the orders to the ten cadets at the oars. When he commands "Toss!" the ten oars must spring skyward as one; when he commands "Let fall!" they must strike the gunwale with a single thud. And these oars are no light spoon-blade sculls, but are fourteen feet of heavy ash, veritable telegraph poles. Doubtless were you to try to toss one yourself, without knowing the knack of it, it would play seesaw with you over the gunwale. wrhon the individual crews have learned how
Each youngster bends to his oar as if his life depended upon his cutter's being first, and the coxswain calls stroke and excitedly urges them on to greater effort, fail to have enough wind left at the finish to announce their triumph with a lusty cheer.

For the drill under sail, oars are tossed and boated, and at the command of "Up masts!" each cadet spring to his place, the masts are whiske from the thwarts and stepped, topmasts raised, shrouds made fast an sheets hauled flat aft, and in veritable "presto change"

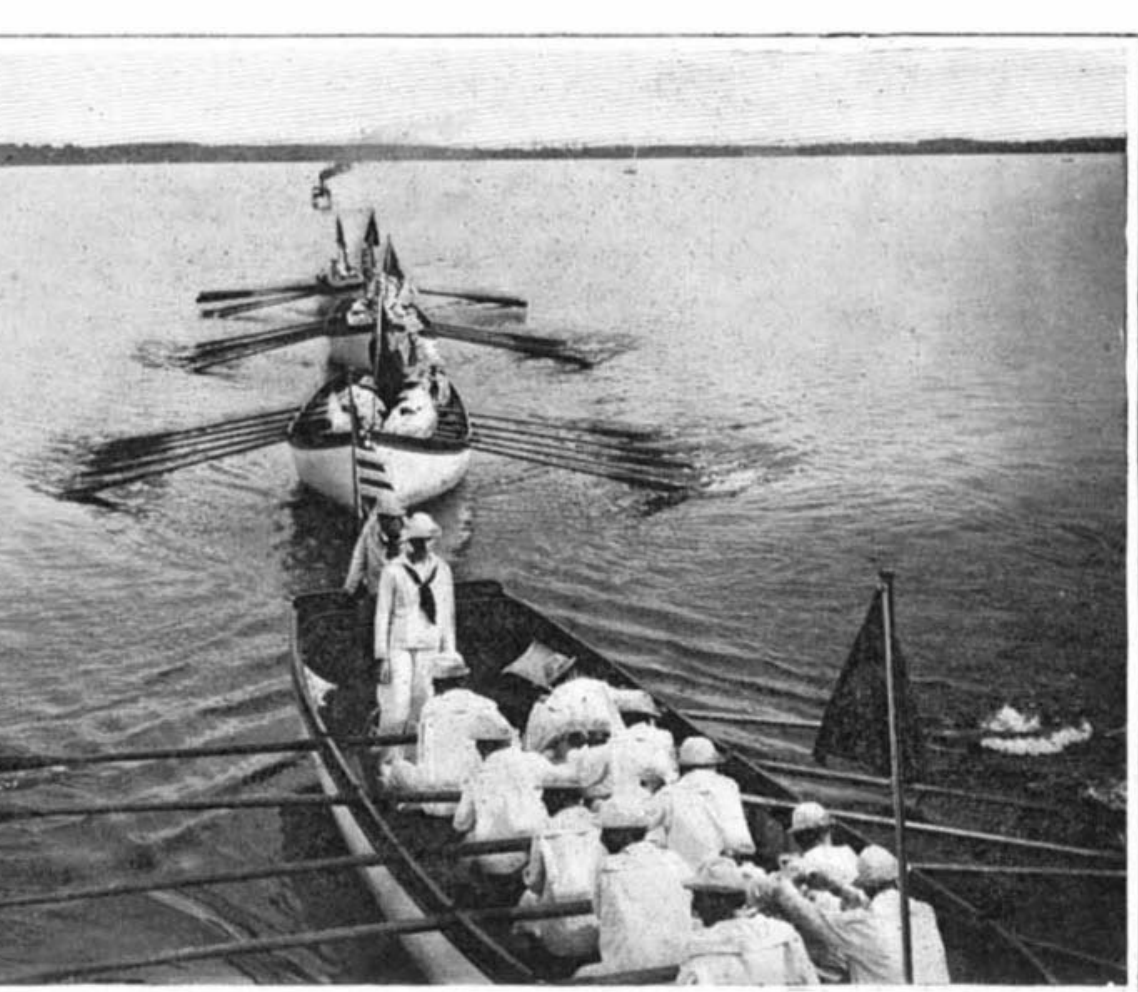

(1) Instructor's Love into Line or Column and Change Direction in Response to Signals from
Launch, Just as Ships of a Squadron would do on Signal from the Flagship. yet with all this exertion the victorious crew never

the bottom, the cadets on the thwarts quickly toss their ars, boat them, spring overboard, and, clinging to the gunwale, rush the cutters high on shore. Then they grasp their rifles and form a long skirmish line, popping away, and advancing determinedly on the enemy. When he has been successfully repulsed, in other words, when the blank ammunition is all expended, they shove off again, and as the boats float free, they clamber over the gunwale, dripping wet, and thoroughly happy.

The calets not confine themselves to boating alone, water polo, tilting matches, swimming races, baseball, tennis, and in fact all the outloor sports dear to a boy's heart. The social feature is not neglected either, and the cadets are rermitte to invite admir. ing femininity for pleasure sails in their cutters, and to a weekly dance or cotillon in the cadet gym. nasium. In the forenoons there is some studying, but not enough to do more than make the rest of the day more attractive.

As for discipline, the cadets are require to observe the rules of naval courtesy and to walk and stand erect, to be prompt and precise. They are organized into a naval battalion of four sections, and form and march to meals, and each day at sunset they are drawn up in line for the firing of the evening gun and the lowering of the colors. Whenever a cadet desires to go beyond the limits for social or other reasons, he must fashion the ten-oare rowboats have taken unto them selves wings, and are scudding over the lake. A cadet tends the main sheet, another the fore sheet, anothe the jib. They must not belay their sheets, but must stand ready to let them fly the instant the coxswain commands. Another calet in the bow keeps a bright lookout ahead. The rest of the crew keep lown in the boat, climbing to windward when the coxswain wants a shift of ballast, and ready, at any instant, to lend a hand in brailing up or lowering away.

Then the cadets are taught besides to splice and to tie knots, and the other things of marlinspike seaman- have a pass signed by the commandant, but these passes are freely granted, the only condition being that they shall not be abused. The cutters were carried down on flat cars, and each day the cadets gave drills in the Grand Basin of the Exposition. This was the first time that naval craft had ever appeare among the launches and gondolas of an exposition lagoon, and during each afternoon drill thousands of spectators gathere to see them. At several of the drills distinguished visitors were tendered the honorary command of each cutter for a race between the crews. On one occasion, Gen. Edmund Rice,
Last summer the cadets spent a week at St. Louis.

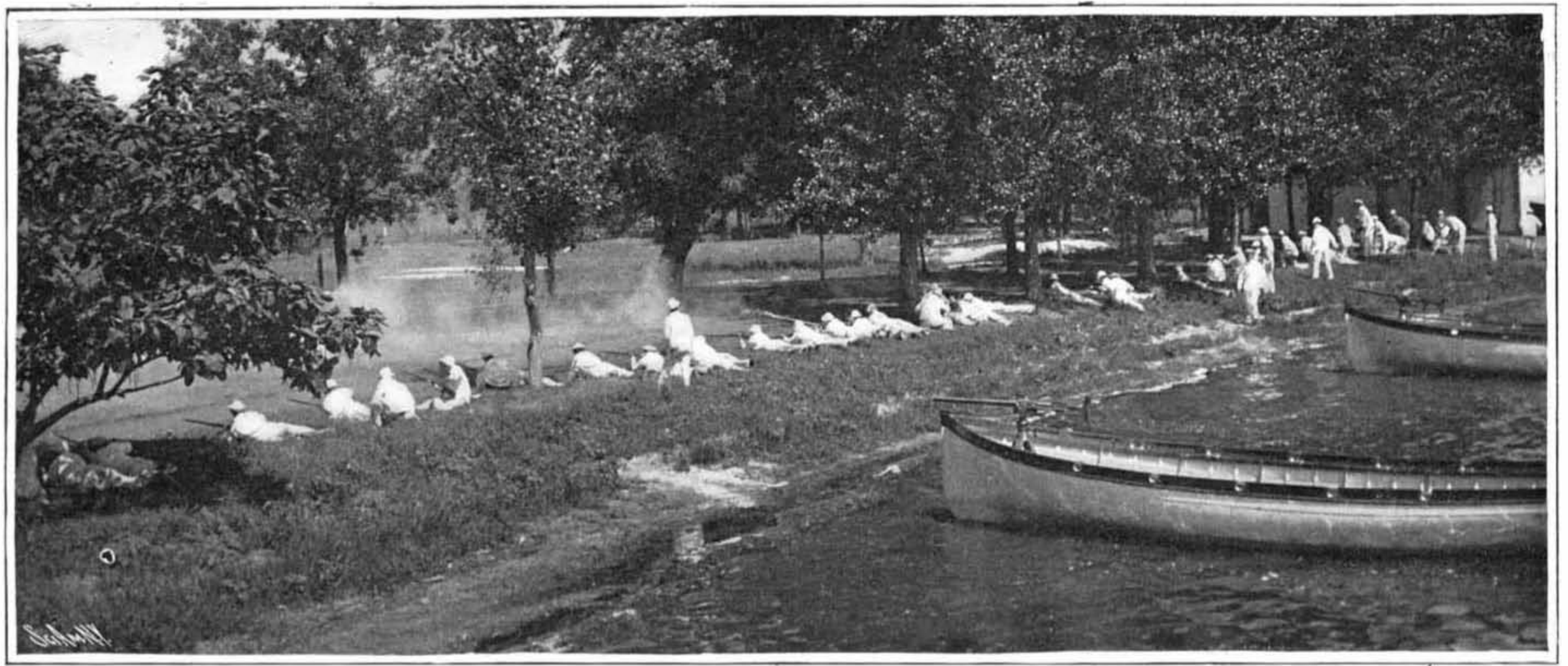

Landing Drill. Skirmish on Shore. When Ammunition is Expended the Cadets Return to the Boats: MANNING OARS AND HALYARDS AS A SUMMER OUTING.

to give way together, and to back water port and give way starboard, in other words, to handle their cutters quickly in response to commands; the cutters are drilled together. Various combinations of gayly-colore sig. nal flags are displayed at the mast of the instructor's launch, and in response to these the cutters maneuver into various formations, just as the ships of a squadron would o on signal from the flagship. All of this is interesting enough; but during the race under oars, a feature of almost every drill, no cadet ever remembers that handling a fourteen-foot oar is anything like work. into the mysteries of the sextant, and of "shooting the sun." But the most interesting arill of all perhaps is when the Hotchkiss rapid-fire guns are mounted in the bows of the cutters, and each man at the oars has a rifle beside him on the thwart and a goodly supply of blank ammunition. A landing is to be made, and an attack on an imaginary enemy on shore. The Hotchkiss gun crew begins to pound away at once, shot afte shot is fired each time the cutter staggers between the recoil of the gun and its own momentum. Finally, as the cutters approach the shore and the keels grate on the President's representative at the Exposition, reviewe the calets, and in the race that conclude the arill his cutter was first to cross the line, the gray. haire general taking almost as keen an interest in the outcome as did the excited youngster in the cox. swain's box.

Aluminium foil is used largely as a substitute for tin foil. One kilogramme-2.2040 pounds-of the metal is spun into 32 square meters of thin sheet. Some of the heets achere together, and this is worked into powder. 
Particulars of Some of the Cars Built for the Gordon Bennett Cu p Hace.

Active preparations are now being made for the Gordon Bennct Cup race. The eliminating trials in France will be held over a circuit in the Auvergne region on the 16 th of June, and 24 cars are to run. These conLevassor; Gobron-Brillié; Richard-Brasier; BayardClement; Darracq; Renault; Automoto; De Dietrich, and Hotchkiss. The prizes which are to be awarded to the winners in this event will be nearly $\$ 30,000$ Most of the cars have been finished or are well under way, and we give herewith some of the leading features of several.

The three Panhard \& Levassor cars somewhat resemble last year's type which were winners in the Ardennes Circuit and the Vanderbilt Cup. They have been modified to some extent and improved in the details. The motor has four cylinders of 170 millimeters (6.8 inches) diameter and stroke; it is said to give 120 horse-power at 1,200 R. P. M. Among the modifications we may note that the finned radiating coils have been replace by a honeycomb radiator having a great cooling surface. An improve form of hydraulic regulator is used. The front of the car remains about the same, but the rear part has a pointed shape. The driving clutch is forme of friction plates, as this form has already proved successful. As in last year's car, the transmission from motor to rear axle is by a universally jointed propeller shaft. Magneto ignition is employed. The frame has been hung as low as possible so as to give the greatest steadiness in making the curves. The Panhard cars will be driven by Heath, Teste, and Henri Farman. The Richard-Brasier cars have also been considerably improved. The motor has four cylinders of 160 millimeters diameter and 140 stroke (6.4 by 5.6 inches) and gives from 90 to 100 horse-power at 1,200 R. P. M. A Simms-Bosch magneto supplies the ignition, with the new Brasier spark-break device. M. Brasier has also designed a new form of carbureter which is said to be much superior to the old. It uses a series of convergent jets. The governor of the motor acts upon the inlet valves, and the latter are mechanically operated. The chassis is lowere and has a relatively small wheel base, this being 2.65 meters ( 8 feet 10 inches), while the tread being 2.65 meters ( 8 feet 10 inches), while the tread
is 1.25 meters ( 4 feet 2 inches). The front and rear wheels are very nearly 3 feet in diameter. These cars are considerably under the regulation weight of 2,204 pounds. The construction is very solid and the exterior form somewhat resembles Théry's car of last year in which the reservoir is built around the driver's seat in the rear, thus obtaining a gain in weight. Therry, Callois, and Stead will drive these cars. But one racer has been entere by Charron, Girardot, and
Voigt. It has an extra large four-cylinder motor, in which the cylinders are mounted separately. The inlet valves, which are mechanically operated, are symmetrical with the exhaust valves. All the working parts are protecte by metal cases. The ignition is by parts are protected by metal cases. The ignition is by is 1,000 R. P. M., and at this speed the motor gives 90 horse-power. At 1,600 R. P. M. it gives 120 horse-power. The wheel base is relatively short, and this is well alapted for the many curves of the Auvergne circuit. A propeller shaft is use to transmit the power to the rear axle. The car has four speeds and a reverse. Girardot is to pilot this car. The Hotchkiss cars, three in number, are rate at 120 horse-power. The weight of the car is not much under the require limit. It is a little longer than last year's model, but about as wide. The wheels measure 34 inches front and 36.4 rear. This year the bonnet will not have a pointed form, but will be the standard Hotchkiss shape, namely, cylindrical, with a honeycomb radiator in front. A propeller shaft and bevel gear drive is used, and the speed changing device, which is very strong, has two sliding gear sets, and gives four speeds and reverse.

Among the English cars which will take part in the eliminating trials on the Isle of Man on the 30th of Nay, we may mention the Napier, which has a four cylinder motor of 165 millimeters ( 6.6 inches) diamete and 150 stroke (6.0 inches). Running at $1,000 \mathrm{R}$. P. M., it gives about 120 horse-power. The upper parts of the cylinders are cast in pairs. To give a good distribution of the weight, the motor has been shifted back toward the rear to some extent. The radiator, of the honeycomb form, is now at the rear of the front axle. This arrangement is claime to give less fatigue on the tires when making the curves. A turbine pump worked by chain from the motor assures the water circulation. The inlet is controlle by a hande place on the steering wheel. The governor is centrifugal, and has an accelerating device which is worked by a pelal. Three speeds and reverse are used, with bevel gear drive. This car is of light weight, not over 2,000 pounds. It has a wheel base of 110 inches and a tread of 58 inches, with 35-inch front wheels and 34-inch rear The Wolseley cars are distinguished by the use of a horizontal motor of four cylinders. Diameter and
stroke are both 6.4 inches. At 1,000 R. P. M. it gives from 115 to 120 horse-power. The crankshaft is of pickel-steel. Chain transmission is another feature of the Woiseley car. It has four speeds and reverse. The wheel base is 9 feet and the tread 57 inches. The motor is place somewhat farther in front than last year, so

As to the German cars, two Mercedes have been already selecte by the German Automobile Club, while the third is to be chosen in the eliminating trials which are to be held shortly. A circuit has been chosen to the north of Homburg for this purpose. The two Mercedes cars will be mounted by Jenatzy and Baron de Caters.

America will this year be represente in the great international race by one Locomobile and two PopeToledo cars of high power, which have beén specially built for the event. The former machine is of 150 horse-power, and is constructed of nickel-steel practiand built under his supervision for Dr. Harold E. Thomas, of Chicago, who has entered it in the Gordon Bennett race of July 5, and the Pike's Peak hill climb to take place in September.

\section{A SIMPLE RHEOSTAT}

L. H. Batchelder, of Hamline University, St. Paul, Viinn., thus describes the rheostat in the accompanying illustration: "I have long had in use in my laboratory a simple and inexpensive rheostat for main taining a steady current of electricity. It is exceedingly convenient, for example, for maintaining a stead current in the quantitative analysis of copper or nickel salts; also in calibrating ammeters with the silver or copper voltameter. The materials required are a hardwood block about three by six inches and an inch thick, a bit of copper wire, a few drops of mercury and three or four feet of No. 20 or 25 Germansilver wire. The wire must, of course, be kept bright

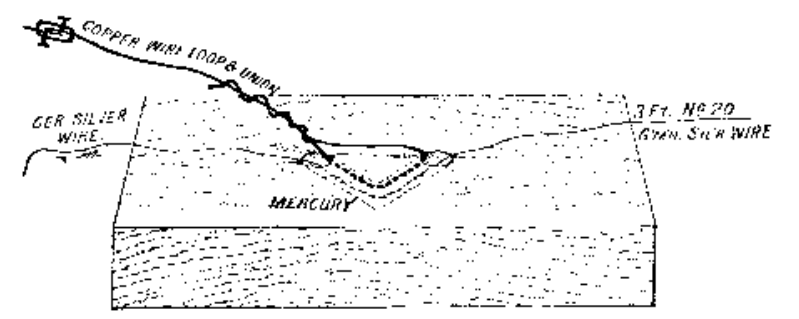

AN EFFECTIVE RHEOSTAT.

for good contact with the mercury. It is drawn to the left or right to be out or in the circuit as may be
require to keep the current at a fixe value as shown by the ammeter in circuit."

\section{Decision of the Automoblle Club of
Regarding an International Race.}

The controversy which has been going on for thre months past relative to the Gordon Benneit cup an the different racing events has not by any mean ceased. At its meeting of March 1 the Automobile Club of France made a new and important decision. This is to the effect that the committee of the club believes, in the present state of events, an annual rac ing event to be essential for bringing out the leadin ideas and showing the progress of the industry. But, on the contrary, numerous events are ruinous for the constructors, without offering a renewe technical interest. If a single race is authorized outside of the Grand Prize, it is impossible to forbid others of the same kind. The multiple races, on account of their insufficient organization, will doubtless bring about catastrophes which will exasperate the populations and stir up public opinion against automobile events. The government will then be obliged to forbid the great annual race which is necessary for the prosperity of the industry which assures the existence of hundred of thousands of workmen. The Automobile Club of France, upheld by the allied French and foreign clubs, by groups of the leading parties interested, and by the syndical chambers of industry, alone possesse sufficient quality and capacity for a good organizatio of a racing event. Owing to its influence such an event is sure to be a success, and bring great numbers of persons from other countries, to the benefit of the hom industry. The safety of the public roads is a poin which must be considered. Again, leading constructor express the lesire to have but one race in France each year, this to be an open event, with no others. Accord ingly the club declares that it is essential that the French government give its patronage exclusively to the great annual race of the club and send its delegates to this event; that it forbid all other races except the club's annual event; and that the promoters of othe races abandon these projects and give their aid to the annual race organize by the club. The committee cides that in case its appeal is not favorably received, it will take the following measures, the importance of which is not to be overlooked: The constructors, organizers, chronometerers, proprietors, and conductors who take part in any other races except the annual event which the club organizes (for 1905 this will be the Gordon Bennett Cup race) will in the future be excluded from all events which are organized by the club or under its patronage. This measure is to be officially communicated to all the allied French and foreign clubs. The Automobile Club opens a subscription list for this year's event and heads the list with $\$ 5,000$. The above decision noes not apply to touring events. As a result of this decision, the Gordon Bennett Cup will be the only race organized by the club this year, and its rules will not be changed. Next year Prize, which will be an international and open event. The sum of $\$ 20,000$ which had been offered by the The sum of $\$ 20,000$ which had been offere by the
Paris journal, the Auto, for the Grand Prize, will be Paris journal, the Auto, for the Grand Prize, will
devoted instea to the French eliminating trials.

$$
\text { Explosion of Gas Buoys. }
$$

A recent explosion of gas buoys is being made the subject of investigation by the Canadian government. At the time of the explosion, the buoys had been fille with gas at a pressure of 180 pounds to the square inch, and a third was being filled when one of the other two buoys exploded, the rupture taking place along a welded seam four feet in length. Flying metal penetrate the adjoining buoy, causing it also to explode. The accident is considered to be due to deof the government, in its recent adoption of lowof the government, in its recent adoption of low-
pressure acetylene gas buoys, is a wise one. These buoys carry a charge of acetylene in a central tube on a grating. When the buoy sinks to a certain depth, sufficient water enters automatically to generate gas from the carbide. The gas expels the water; and automatically cuts off the intake of water. As the gas is consume the water again rises, touching the carbide and producing more gas. The pressure does not exceed about three pounds to the square inch, and some
of these buoys used last season have given excellent satisfaction.

\section{The current Supplement.}

The opening article of the current Supplement, No 1531 , describes an economical coal-handling plant. A variable-spee gear giving all speeds from zero to maximum is illustrated and fully explained. Perhaps the most efficient device which has thus far been used in detecting the presence of radio-activity is the electroscope. One of the most valuable articles in the current SUPPLEMENT is that which describes the construction of an electroscope for experiments on radio-activity. $\mathrm{Dr}$ O. N. Witt presents another article on the Chemistry of Patinas. Emile Guarini writes on a new thermo-electric battery. A new secret service telephone is the subject of an article by the English correspondent of the Scientific American. When completed, the Japanese battleship "Kashima," recently escribe in the columns of the Supplement, will be the most powerful war vessel afloat. Trials of the armor plate with which the "Kashima" is to be protected were recently carrie out at Manchester. An illustrate article in the SuppLEMENT describes the results obtained. J. E. Gore presents a popular account of stellar brightness and density. Loewy and Puiseux have been for years engage in making a photographic study of the moon. The Paris correspondent of the ScIen TIFIC American reviews the results of their work. The third and last installment of A. J. Hipkins's article on Musical Instruments, Their Construction and Capabilities, is presented. He deals with keyboard instruments. An excellent paper by Sir William Lockyer is that on "Our Sun and Weather."

Submarine Mines for the German Navy.

Owing to the widespread success that has attended the employment of submarine mines uring the RussoJapanese war, the German naval authorities have decide to devote greater attention to the subject of sea mines than has been their practice hitherto. A mine company comprising two hundre men has been formed, and will be statione at Cuxhaven, this naval port having been selected as a base from which the entire defensive operations of the North Sea will be directed. There are three mine-laying vessels at present in the German navy, but these are to be partially superseded by six torpe-boats, which have been stationed at Cuxhaven for the use of the new mine company. It is anticipate that when the men have been trained to lay mines with quick-moving torpedo-boats, it will be practicable to block the estuary of the Elbe with stahours.

A conference of scientific scholars is being held at Colorado College, Colorado Springs. Leading universities and colleges are represented. A number of valuable papers upon subjects bearing on the scientific problems of the Rocky Mountain country will be read, and the results of the conference give promise of much permanent value. A similar conference held a year ago at this same institution was of such importance that it led to this second series of meetings. 


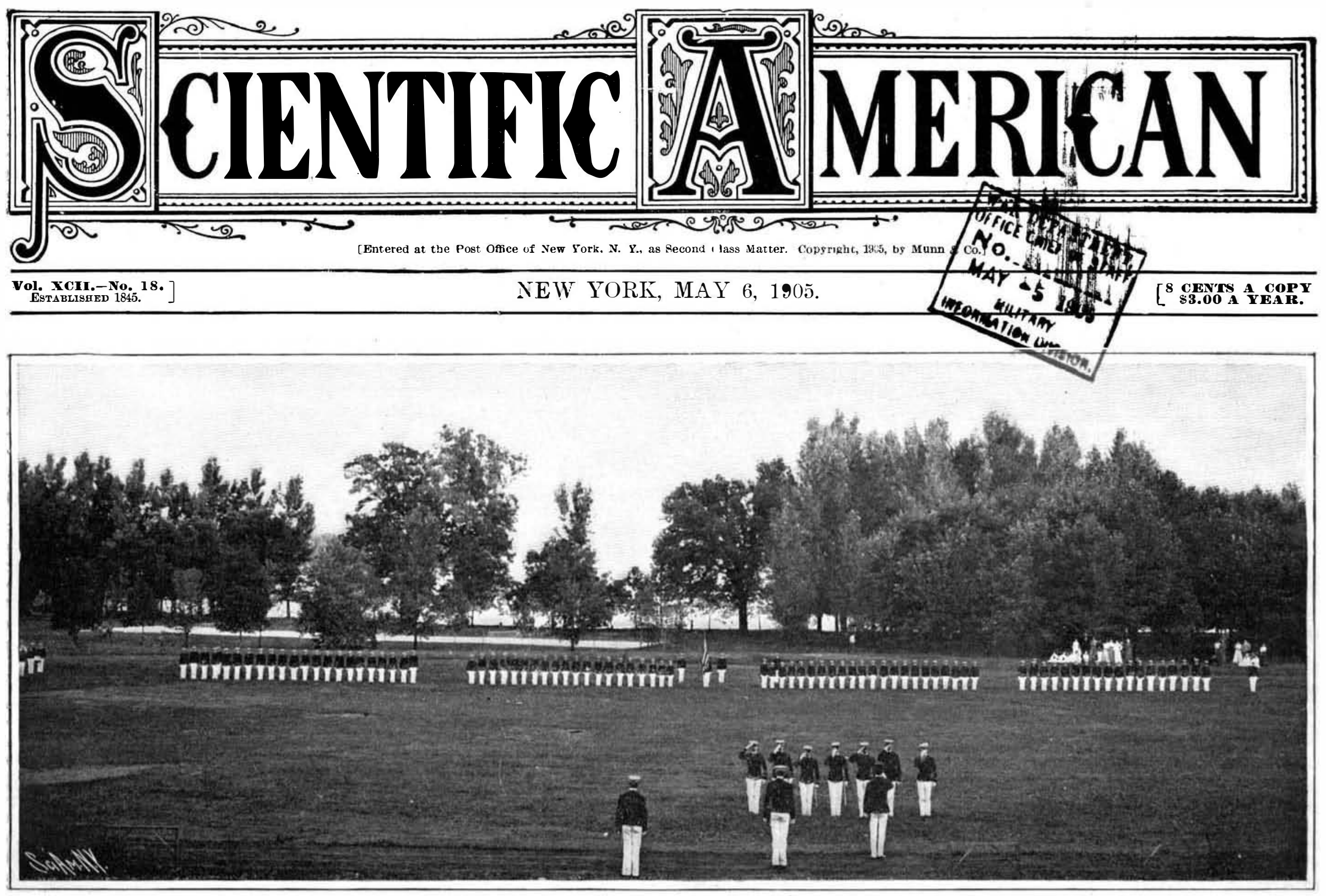

Evening Parade. Colors Are Lowered to the Salute of the Sentinel Gun and the Playing of the "Star-Spangled Banner."

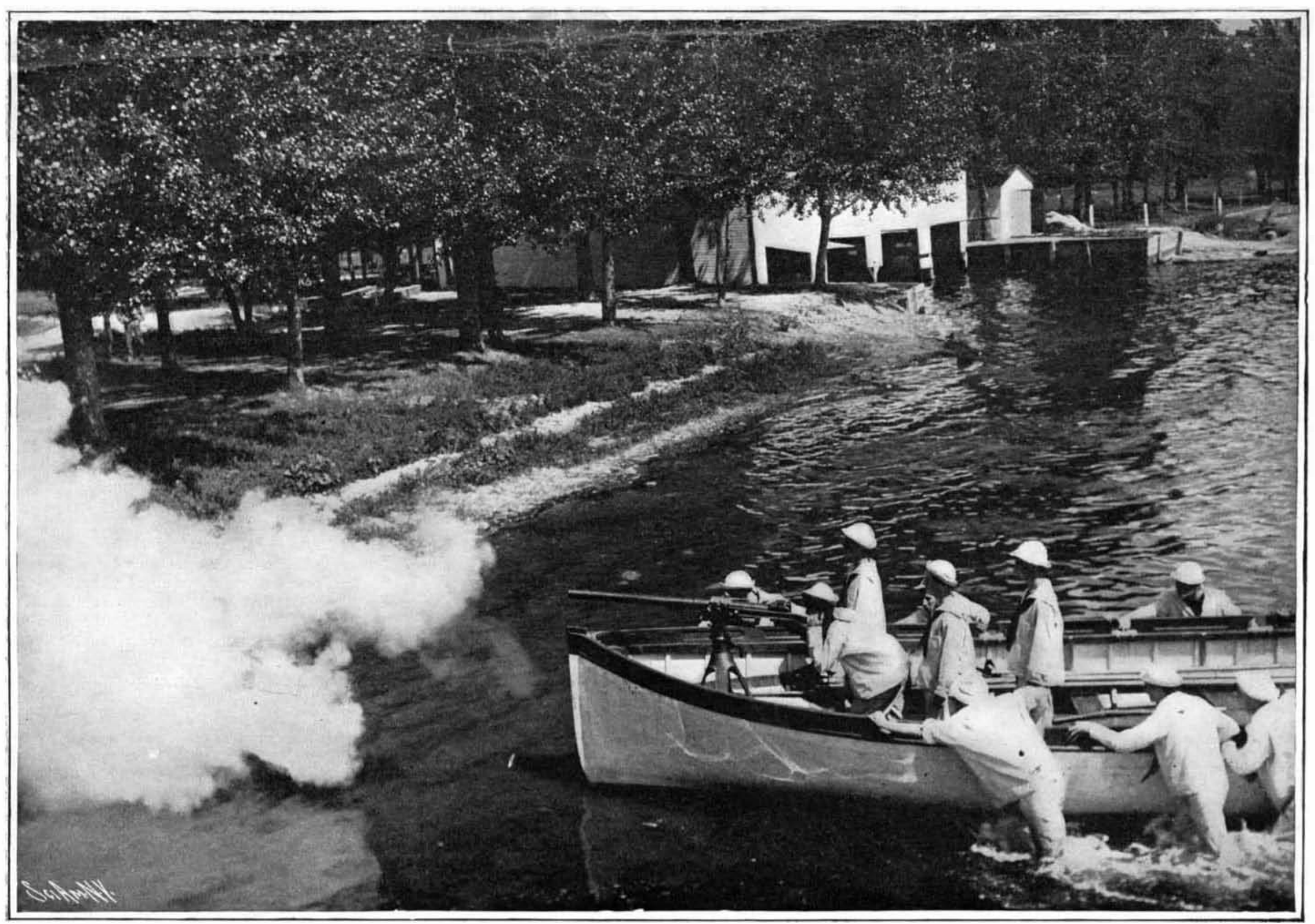

As the Keel Touches Bottom the Cadets on the Thwarts Toss and Boat Their Oars, Leap Overboard and, Grasping the Gunwale, Rush the Lightened Cutter High and Dry on Shore. 